\title{
Peran Humas Polres Metro Depok dalam Mensosilisasikan Physical Distansing di Masa Pandemi Covid-19
}

\author{
Siti Latifah ${ }^{1}$, Febriansyah Nataly ${ }^{2}$, Berliana Lukitawati ${ }^{3}$ \\ ${ }^{1,2,3}$ Sekolah Tinggi Ilmu Komunikasi Indonesia Maju \\ Email correspondent: sitilatifah176@gmail.com
}

\begin{abstract}
Abstrak
Penelitian ini bertujuan untuk mengetahui apa saja peran humas Polres Metro Depok dalam mensosilisasikan physical distancing dimasa pandemi Covid-19. Pendekatan yang digunakan dalam penelitian ini adalah pendekatan deskriptif kualitatif. Sumber data yang diperoleh melalui kata-kata dan tindakan, sumber tertulis serta foto. Teknik pengumpulan data yang digunakan dalam penelitian ini adalah wawancara, obsevasi dan dokumentasi. Teknik pemilihan informan yang digunakan adalah purposive sampling yaitu 3 masyarakat Kota Depok dan 2 orang dari Polres Metro Depok. Teknik vadilitas data menggunakan teknik triangulasi sumber. Teknik analisis data menggunakan model analisis interaktif yang terdiri dari pengumpulan data, reduksi data, penyajian data, dan penarikan kesimpulan. Hasil dari penelitian ini menunjukan dua hal. Pertama, Kegiatan yang dilaksanakan untuk mensosialisasikan physical distancing telah dijalankan oleh Humas Polres Metro Depok sebagian besar melalui media komunikasi, adapun media yang telah digunakan seperti melalui media cetak, elektronik, dan media sosial. Kedua, Media sosial memiliki peran sangat besar karena sifatnya yang dapat menyebarkan pesan secara massive. Pemanfaatan media sosial sebagai sarana sosialisasi physical distancing untuk menumbuhkan awareness publik terhadap suatu wabah yang sedang melanda di Indonesia. Saran dari penelitian ini yaitu Humas Polres Metro Depok perlu melakukan identifikasi masalah dan fakta di lapangan lebih baik lagi, merancang solusi-solusi dari beberapa kemungkinan permasalahan yang terjadi ketika kegiatan dilaksanakan, melalukan pemetaan karakter pada target sosialisasi yang akan di tuju, memaksimalkan kerja dan fungsi dalam pensosialisasian, menciptakan sosialisasi yang menarik bagi masyarakat melalui media, membuat koordinasi khusus untuk mengevaluasi dalam pensosialisasian physical distancing.
\end{abstract}

Kata Kunci: peran humas, sosialisasi, physical distancing

\begin{abstract}
This study aims to find out what are the public relations roles of Metro Depok Police in socializing physical distancing during the Covid-19 pandemic. The approach used in this research is the qualitative descriptive approach. Sources of data are obtained through words and actions, written sources as well as photos. The data collection techniques used in this study are interviews, observation, and documentation. The informant selection technique used is purposive sampling, namely 3 people of Depok City and 2 people from Depok Metro Police. Data validity technique using source triangulation technique. Data analysis techniques use an interactive analysis model consisting of data collection, data reduction, data presentation, and inference. The results of this study show two things. First, the activities carried out to socialize physical distancing have been carried out by the Public Relations of Metro Depok Police mostly through communication media, as for the media that have been used such as through print, electronic, and social media. Second, social media has a huge role because of its nature which can spread the message massively. Utilization of social media as a means of socializing physical distancing to foster public awareness of an outbreak that is currently engulfing Indonesia. The advice of this research is that The Public Relations of Metro Depok Police needs to identify problems and facts in the field better, design solutions to several possible problems that occur when activities are carried out, through character mapping on the target of socialization to be intended, maximizing work and function in socialization, creating attractive socialization for the community through the media, making special coordination to evaluate in the socialization of Physical Distancing
\end{abstract}

Keywords: role of public relations, socialization, physical distancing 


\section{Pendahuluan}

Covid-19 merupakan subjek medis sehingga permasalahan ini paling tepat diselesaikan dengan menggunakan payung bidang kedokteran, perspektif kedokteran menyatakan, Covid-19 efektif diatasi melalui isolasi dan karantina medis. Isolasi adalah pemisahan orang sakit dengan penyakit menular dari orang yang tidak terinfeksi untuk melindungi orang yang tidak terinfeksi dan biasanya dilakukan di rumah sakit. ${ }^{2}$ Karantina berarti pembatasan pergerakan orang yang diduga telah terkena penyakit menular tetapi tidak sakit, baik karena mereka tidak terinfeksi atau karena mereka masih dalam masa inkubasi. ${ }^{2}$ Namun, Covid-19 juga dipahami sebagai subjek sosial yang menuntut penyelesaian dari bidang keilmuan sosial. ${ }^{2}$

Para ilmuwan sosial memandang perlu diterapkannya pyhsical distancing dalam pencegahan Covid-19 untuk mengurangi interaksi antara orang-orang dalam komunitas yang lebih luas, di mana individu mungkin tertular tetapi belum diidentifikasi sehingga belum terisolasi. ${ }^{3}$ Cara ini efektif untuk mengurangi transmisi Covid-19 yang terjadi melalui percikan (droplet) dari mulut atau hidung saat batuk, bersin, dan berbicara. Transmisi penyakit dengan cara ini umumnya terjadi ketika ada kontak dalam jarak dekat kurang dari dua meter.

Lebih dari itu, ada yang menyarankan penerapan social containment (pengungkungan sosial) dalam skala besar. Social containment adalah intervensi yang diterapkan pemerintah ke seluruh komunitas, kota atau wilayah, yang dirancang untuk mengurangi interaksi pribadi, kecuali interaksi minimal untuk memastikan pasokan vital. Para pakar menegaskan bila kebijakan pencegahan Covid-19 gagal, maka pendekatan terbaik berikutnya adalah intervensi pemerintah untuk mengurangi angka kematian dan mencegah infeksi berlebih.

Presiden Joko Widodo mengerahkan aparat Polri untuk membantu menerapkan dan mensosialisasikan physical distancing di tengah pandemi Covid-19. Polri dibagi menjadi beberapa bagian seperti Mabes Polri, Polda, Polres maupun Polsek yang mana tugas dan tanggung jawab atas satu wilayahnya berbeda. Mabes Polri atau Markas Besar Polri yang berkantor pusat di Jakarta dan membawahi semua Polda dari Sabang sampai Marauke. Lalu Polda atau Kepolisian Daerah wilayah hukumnya adalah satu provinsi, misalnya Polda Jabar maka wilayah hukumnya adalah seluruh Propinsi Jawa Barat. Lalu Polres atau Kepolisian Resort wilayah hukumnya mencakup wilayah satu Kabupaten/Kotamadya, tidak terkecuali Polres Metro Depok dimana Polres Depok membawahi 6 Polsek atau Kepolisian Sektor yang meliputi 11 kecamatan di Kota Depok.

Berdasarkan data bulan Agustus 2020 Depok pernah menjadi salah satu angka covid-19 tertinggi di Jawa Barat, Depok juga penghubung antara Jakarta dengan Bogor, letaknya yang ditengah menjadikan depok rentan oleh penyebaran covid-19, sehingga peran Polres Metro Depok dinilai sangat penting karena kepolisian bersentuhan langsung dengan masyarakat, dan masyarakat cenderung lebih patuh terhadap sebuah aturan atau kebijakan apabila aparat kemanan atau penegak hukum yang menyampaikan. Dalam mensosialisasikan physical distancing pada masa Pandemi ini, Polres Metro Depok sangat berperan untuk memelihara keamanan dan ketertiban masyarakat, penegak hukum serta memberikan perlindungan, pengayoman dan pelayanan bagi masyarakat dalam rangka terciptanya keamanan di Depok. Berbagai upaya telah dilakukan oleh pihak kepolisian dalam meningkatkan rasa aman seperti pelayanan pos polisi, aplikasi online, call center, penyebaran informasi di media sosial, serta pelayanan administrasi di markas/kantor. Semua bagian di Porles Metro Depok ikut turut andil dalam mensosialisasikan pyschal distancing ini. ${ }^{16}$

Dengan adanya penerapan physical distancing tersebut, maka Humas Polres Depok memiliki tugas yang lebih andil dibandingkan dengan devisi lain. Humas Polres Depok harus memastikan bahwa personil polres telah dikerahkan untuk mendisplinkan dan memberi edukasi kepada masyarakat terkait penerapan pyhsical distancing. Humas Polres Depok juga melakukan koordinasi dengan stakeholder dan tim gugus tugas Covid-19 di daerah Depok dalam memberikan edukasi kepada masyarakat. Bagi 
anggota-anggota Polres di desa atau di kelurahan akan membantu mensosialisasikan aturan-aturan dan kebijakan pemerintah tentang physical distancing.

Tujuan penelitian ini adalah sebagai berikut: (2) Untuk mengetahui peran Humas Porles Metro Depok dalam mensosialisasikan physical distancing. (1) Untuk mengetahui hambatan yang dihadapi Humas Porles Metro Depok dalam mensosialisasikan physical distancing.

\section{Metode}

Pendekatan yang digunakan dalam penelitian ini adalah pendekatan kualitatif, penelitian kualitatif adalah penelitian yang menggunakan latar alamiah dengan maksud menafsirkan fenomena yang terjadi dan dilakukan dengan jalan melibatkan berbagai metode yang ada. ${ }^{11}$

Sifat penelitian ini adalah deskriptif. Data yang dikumpulkan berupa kata-kata dan gambar, bukan angka-angka. Semua yang dikumpulkan berkemungkinan menjadi kunci terhadap apa yang sudah diteliti. Dengan demikian, laporan penelitian akan berisi kutipankutipan data untuk memberi gambaran penyajian laporan tersebut. ${ }^{12}$

Penentuan informan dalam penelitian ini menggunakan teknik purposive sampling. Teknik purposive sampling ini adalah teknik mengambil informan atau narasumber dengan tujuan tertentu sesuai dengan tema penelitian karena orang tersebut dianggap memiliki informasi yang diperlukan bagi penelitian. Dalam hal ini peneliti memilih informan yang dianggap mengetahui permasalahan yang akan dikaji serta mampu memberikan informasi yang dapat dikembangkan untuk memperoleh data. Untuk memperoleh data dan melengkapi penelitian ini, penulis melakukan wawancara mendalam dengan key informan dan informan. Key informan merupakan informan yang berwibawa dan dipercaya mampu membukakan pintu kepada peneliti untuk memasuki obyek penelitian. ${ }^{1}$

Data menurut sumbernya dan yang dikumpulkan jenis data dapat di bedakan menjadi dua, yaitu data primer adalah hasil peneliti atau observasi dengan wawancara mendalam (indepth interview) dengan pihak-pihak yang terkait. Pada wawancara mendalam yang berlangsung diajukan pertanyaan- pertanyaan secara detail untuk mendapatkan data yang diinginkan, akurat dan sesuai dengan format penelitian. ${ }^{15}$ Data sekunder diperoleh melalui data berbentuk dokumentasi melalui buku, web, artikel, dan foto untuk mendukung penelitian yang diangkat. Dokumen menjadi alat untuk melengkapi keterangan yang telah diberikan oleh informan. ${ }^{10}$

Teknik pengumpulan data yang peneliti gunakan dalam penelitian ini adalah Observasi, Wawancara Mendalam dan Studi Pustaka. ${ }^{8}$

Setelah melakukan pengumpulan data, seluruh data yang terkumpul kemudian diolah oleh peneliti. Data dianalisis menggunakan metode deskriptif kualitatif yaitu dengan mendeskripsikan secara menyeluruh data yang didapat selama proses penelitian. Miles dan Huberman dalam Sugiyono mengungkapkan bahwa dalam mengolah data kualitatif dilakukan melalui tahap reduksi, penyajian data, dan penarikan kesimpulan. ${ }^{12}$

Analisis triangulasi yaitu menganalisis jawaban subjek dengan meneliti kebenarannya dengan data empiris (sumber data lainnya) yang tersedia. Di sini jawaban subjek di-cross-check dengan dokumen yang ada. Penulis menggunakan triangulasi dengan sumber, di mana informasi yang diperoleh dari sumber yang berbeda dibandingkan dan dicek ulang derajat kepercayaannya. ${ }^{14}$ 


\section{Hasil dan Pembahasan}

Humas seperti yang peneliti ketahui bahwa ada dua macam tipe humas yaitu Humas yang berada di instansi pemerintah dan Humas non pemerintah (lembaga komersial) yang dimana keduanya memiliki perbedaan yang sangat jelas baik dari fungsi maupun tugas bahwa di humas Pemerintah tidak adanya unsur komersil karna humas di Pemerintahan menekankan pada publik servis dan pelayanan bagi masyarakat, sedangkan humas Non Pemerintah sangat kental dengan hal yang komersial. Seperti halnya kalimat diatas, penulis secara langsung bertanya kepada humas Polres Metro Depok bahwa memang benar adanya perihal humas yang berada di Instansi Pemerintahan memang tidak ada unsur komersil seperti halnya di humas-humas yang berada di non pemerintah, walaupun di humas Pemerintah pun juga melakukan hal yang sama dalam kegiatan publikasi, promosi dan periklanan. ${ }^{13}$

Humas Polres Metro Depok berada dibawah Kabag Ops (Kepala Bagian Operasi) Polres Metro Depok. Humas Merto Depok dibagai menjadi sub bagian yaitu Subbaghumas (Sub Bagian Hubungan Masyarakat) Bertugas mengumpulkan dan mengolah data, serta menyajikan informasi dan dokumentasi kegiatan Kepolisian yang berkaitan dengan penyampaian berita di lingkungan Polres; dan meliput, memantau, memproduksi, dan mendokumentasikan informasi yang berkaitan dengan tugas Polres.

Humas Polres Metro Depok memegang kendali penuh dalam menangani masalah yang berhubungan dengan media untuk memasilitasi wartawan, media cetak, media sosial dan konten web untuk Polres Metro Depok. Humas menjalin hubungan secara intensif karna untuk menjembatani awak media untuk kebutuhan media yang berkaitan dengan pemerintah.

\section{Peran Humas Polres Metro Depok dalam mensosialisasikan Physical Distancing di masa Pandemi Covid-19}

Humas Polres Depok dalam sosilisasi physical distancing ini dapat dikatakan sebagai teknisi komunikasi, yang mana menjadikan praktisi humas sebagai Jurnalist in Resident. Disini Humas Porles Depok cukup baik melakukan peran tersebut hal tersebut dapat dilihat dari media-media yang digunakan oleh Porles Metro Depok. Mulai dari media cetak, elektronik maupun penanfataan social media.

Humas Polres Metro Depok juga memiliki binaan wartawan, Jurnalis dari TV Nasional maupun lokal bahkan Radio, yang mana jurnalist tersebut dibina oleh Polres Metro Depok untuk memberitkan segala kegiatan yang ada di Polres Metro Depok termasuk sosilisasi physical distancing.

Humas Polres Metro Depok memiliki peranan yang sangat penting dalam melakukan komunikasi antara institusi dengan publiknya dan media maupun sebaliknya, karna peran humas mewakili institusi dan memiliki peran yang penting baik di lingkup internal maupun eksternal. Cara yang dilakukan Humas Polres Depok adalah memanfaatkan hubungan dengan media. Menjalin hubungan dengan media merupakan hal yang sangat penting bagi humas, karna dengan menjalin hubungan yang baik dengan media dapat memudahkan suatu organisasi/institusi dapat berkomunikasi dengan masyarakatnya. Selain memudahkan dalam berkomunikasi dengan masyarakat hubungan yang baik dengan media juga untuk menunjang kegiatan Humas Polres Depok termasuk dalam sosialisasi physical distancing ini.

Humas Polres Depok dalam menjalin hubungan yang baik dengan media berusaha seoptimal mungkin dalam memberikan informasi kepada awak media, seperti informasi yang dibutuhkan oleh media sebisa mungkin humas menyanggupi dan memfasililtasi, karna yang media butuhkan adalah informasi sebagai bahan berita mereka dan sedangkan humas membutuhkan media untuk mempublikasikan informasi tentang physical distancing tersebut kepada masyarakat luas.

Untuk peran sebagai penasehat ahli Humas Polres Metro Depok belum menjalankan peran tersebut, karena polri mempunyai staff penasehat ahlinya tersendiri atau biasa disebut Sahli Kaporli, dalam sosilisasi physical distancing Humas Polres Metro Depok beranggapan bahwa masih ada bagian- 
bagian yang lebih tepat untuk menjalankan peran sebagai penasehat ahli karna dalam pandemi Covid19 pemerintah telah membenuk gugus tugas Covid-19.

Sedangkan untuk peran sebagai fasilitor komunikasi, Humas Polres Depok dibantu oleh satuan kerja binaan masyarakat atau yang biasa disebut sat binmas. Sat Binmas lah yang turun langsung kepada masyarakat, hal ini dikarenakan salah satu fungsi Sat Binmas adalah melakukan sosialisasi dengan tema-tema tertentu termasuk physical distancing ini. Humas polres metro depok juga belum menjalankan peran sebagai fasilitor pemecah masalah. Dalam sosilalisasi physical distancing, Humas Polres Metro Depok setidaknya dibantu oleh bhabinkamtibmas yang masih merupkan satuan kerja dati Sat Binmas. bhabinkamtibmas lebih berperan door to door yang artinya dari pintu ke pintu, hal yang dimaksud disini adalah seperti menayakan keluhan-keluhan warga serta pembagian bahan pangan kepada masyarakat akibat dampak covid-19. ${ }^{9}$

Jadi dapat di tarik kesimpulan bahwa Humas Polres Depok belum secara optimal melakukan peran humas yang semestinya. Dalam temuan humas polres hanya melakukan peran humas sebagai teknisi komunikasi (Communications Technician) saja. Sedangkan Penasehat Ahli (Expert Prescriber) belum dilakukan, Fasilitator Komunikasi (Communication Fasilitator), dan Fasilitator Proses Pemecahan Masalah (Problem Solving Process Fasilitator) humas polres beranggapan adalah tugas dari bagian sat binmas. Untuk peran sebagai teknisi komunikasi (Communication Technician) itu sendiri, Humas Polres Depok disini sudah melakukan tugas baik, disini humas Polres Depok memakai media - media yang beragam mulai dari media sosial, media online, poster, baliho, stiker, exbanner, banner, standding banner, majalah internal, pers release, pers conference, mediagathering, media visit, sosialisasi masyarakat, penyuluhan, talk show. Humas Polres Metro Depok sudah menggunakan exbanner, benner, dan standing banner juga di gunakan oleh Polres Metro Depok untuk memberikan informasi tentang Physical Distancing maupun peraturan, himbauan, prosedur, visi, misi, dan lainnya bisa kita lihat dipolres, polsek, sat lantas dan di jalan ada banyak yang bisa kita temui.

Untuk media lain yang di gunakan oleh Polres Metro Depok seperti pressrelease, press conference, media gathering, media visit itu juga digunakan oleh Polres Metro Depok bisa kita lihat di website Polres Depok yaitu polestradepok.net di situ kita bisa melihat bahwa hasil kegiatan yang pernah dilakukan oleh Polres Metro Depok dalam pensosialisasian Physical distancing di posting di website tersebut. Maupun unggahan di media sosial Polres Metro Depok seperti twitter, instagram mauapun facebook. Media - media yang di gunakan oleh polres Depok sebenernya sudah sangat beragam. Namun akan lebih baik apabila Humas Polres Depok melakukan sosialisasi secara langsung ke masyarakat sehingga masyarakat bisa lebih tahu kemana masyarakat mencari informasi polres Depok. Dalam penggunan media online dan media sosial humas polres Depok selalu memantau media tersebut, jadi tidak hanya menyebarluaskan informasi saja tetapi juga harus menganggapi kiriman - kiriman dan komenter dari warga masyarakat pengguna medsos itu sendiri.

Dalam penanaman nilai-nilai dalam proses sosialisasi perlu diperhatikan beberapa faktor yang terkait agar tujuan dapat tercapai, yakni peraturan, sanksi berupa hukuman dan penghargaan, juga konsistensi.

Apabila dilihat lebih lanjut, peraturan tentang physical distancing ini sudah cukup jelas. Pemerintah pusat maupun daerah sudah mengeluarkan peraturan tentang physical distancing, Dari pihak kepolisian pun telah mengeluarkan Maklumat Kapolri tentang anjuran physical distancing. Maka dapat dikatakan peraturan yang mendukung untuk keberhasilan sosilisasi sudah ada, tinggal bagaimana penerapannya kepada masyarakat dan bagaimana masyarakat menjalankan sosiliasi physical distancing tersebut.

Lalu terciptanya hukuman yang dilakukan oleh humas Polres Metro Depok cukup bagi pelanggar yang telah melanggar aturan tentang physical distancing. Hukuman yang ditegakkan kepada masayrakat cukup beragam. Pada mula masa pembatasan sosial sekala besar dilakukan, apabila ada yang melanggar maka akan dikenakan sanksi yang bertuliskan "saya telah melanggar psbb kota depok"

Available online http://journal.stikom-ima.ac.id/ 
dan ada juga hukuman yang bersifat edukasi seperti menyebutkan pancasila hingga membersihkan lingkungan. Walaupun hukuman bagi pelanggar yang tidak menaati aturan sudah jelas namun pada kenyataanya masih banyak masyarakat yang kurang sadar akan pentingnya sosilisasi physical distaning ini. Disinilah Polres Metro Depok selaku penegak hukum harus lebih tegas lagi

Dapat dilihat pula, konsistensi peraturan satu dengan yang lainnya dapat dikatakan sudah cukup baik. Seperti pada mula pandemi Covid-19 melanda Indonesia. Pemerintah mengeluarkan peraturan untuk melakukan social distancing yang kemudian berubah menjadi physical distancing, namun pada kenyataannya angka covid-19 belum turun. Pemerintah pusat, maupun daerah akhirnya mengeluarkan peraturan tentang PSBB. Kesinambungan peraturan sudah cukup baik dengan tujuan dan harapan bahwa covid-19 di indonesia cepat berakhir.

Adapun faktor lain yang mempegaruhi keberhasilan proses sosialisasi seperti prespsi sosial dan sikap atau prasangka. Dalam sosilisasi physical distancing ini sebenarnya dapat dikatakan bahwa persepsi masyarakat cukup berpengaruh besar, namun pada kenyatannya seperti yang kita ketahui bahwa masih banyak masyarakat yang tidak mempercayai adanya Covid-19. Sikap atau Prasangka masyarakat juga sangat penting, walaupun angka Covid-19 di Indonesia terus naik, namun masih ada saja masyarakat yang kurang perduli anjuran physical distancing ini.

\section{Bagaimana Peran Humas Polres Depok dalam sosiliasi physical distancing}

Meskipun masyarakat sudah memahami dan mengetahui betul tentang physical distancing, namun ikatan relasi sosial masih lebih kuat dalam perspektif masyarakat. Peran dari perspektif interaksionis simbolik dalam physical distancing dapat dilihat pada perilaku masyarakat, di mana penggunaan istilah physical distancing menjadi dilema.

Dalam penerapannya. Pertama, masyarakat kesulitan menjalankan physical distancing karena kebiasaan dalam kebersamaan, kerja sama, solidaritas, dan sejenisnya sebagai bentuk dari interaksi sosial. Kedua, bagi masyarakat awam beranggapan physical distancing hanya sebatas menjaga jarak, terlihat pada saat ketika berada di area publik seperti ketika melakukan antrian di anjungan tunai mandiri (ATM). Meskipun, kondisi seperti ini masih menjadi masalah pribadi karena masih ada orang yang tidak mudah untuk melakukannya. Dengan kata lain, terlihat dengan sangat jelas ada persoalan yang sementara dihadapi oleh masyarakat terkait dengan physical distancing. Tidak bisa kita mungkiri bahwa akibat dari physical distancing, masyarakat harus melakukan aktivitas di tempat tinggal masingmasing. Sementara, sebelumnya mereka melakukan aktivitas dengan banyak orang secara bersamasama.

Oleh karna itu Humas Polres Depok mempunyai tugas yang lebih besar lagi, selain dengan terus mensosilisasikan peraturan demi peraturan yang ada, Polres Metro Depok harus siap menghukum masyarakat yang tidak taat dalam menjalankan aturan yang ada. Polres Metro Depok dalam penerapannya juga di bantu oleh RT, Ustad maupun ulama-ulama setempat. Agar masyarakat lebih patuh lagi terhadap aturan yang ada saat ini Humas Poles Depok juga memelihara iklim komunikasi agar senantiasa terbuka, bertekat untuk memegang teguh etika dalam berkomunikasi dan menjalankannya dengan baik, memahami akan adanya kesulitan komunikasi antar budaya, menggunakan pendekatan komunikasi yang berpusat pada penerima pesan, menggunakan teknologi yang ada secara bijaksana dan bertanggung jawab agar dapat memperoleh dan membagi informasi dengan baik dan efektif, Menciptakan serta memproses pesan secara efektif dan juga efisien. Hal ini bisa dilakukan dengan beberapa cara yakni: memahami penerima pesan, menyesuaikan pesan dengan si penerima, mengurangi jumlah pesan, memilih saluran atau media secara tepat, meningkatkan keterampilan berkomunikasi. 


\section{Kesimpulan}

Berdasarkan sajian data dan analisis yang telah peneliti paparkan pada BAB IV, maka peneliti dapat menarik kesimpulan bahwa Humas Polres Metro Depok Dalam Mensosialisasikan Physical Distancing dimasa Pandemi Covid-19 dengan melakukan peranan sebagai teknisi komunikasi. Internal Kepolisian berperan besar dalam sosialisasi physical distancing melalui sarana komunikasi informal dari polisi terhadap masyarakat yang memiliki kedekatan tertentu, hal tersebut mempengaruhi target sasaran untuk mencapai keberhasial sosialisasi. Pemanfaatan media sosial Polres Metro Depok sebagai strategi sosialisasi physical distancing untuk menumbuhkan awareness publik terhadap suatu wabah yang sedang melanda di Indonesia.

Masyarakat kesulitan menjalankan physical distancing karena kebiasaan dalam kebersamaan, kerja sama, solidaritas, dan sejenisnya sebagai bentuk dari interaksi sosial dan bagi masyarakat awam beranggapan physical distancing hanya sebatas menjaga jarak.

\section{References}

1. Ade Heryana, Informan Dan Pemilihan Informan Pada Penelitian Kualitatif 6 (1) : 65-78.2015

2. Australian Government Department of Health. 2020. "Quarantine for coronavirus (COVID-19)" www.health.gov.au di akses pada 15 Agustus 2020 pukul 20.29 WIB.

3. Centers for Disease Control and Prevention (CDC). 2020. "Symptoms of Coronavirus" https://www.cdc.gov di akses pada 8 agustus 2020 pukul 20.03 WIB.

4. European Centre for Disease Prevention and Control. 2020. "Transmission of COVID-19" https://www.europa.eu di akses pada 6 juli 2020 pukul 20.19 WIB.

5. Effendy, Onong Uchjana. Ilmu Komunikasi Teori dan Praktek. Bandung: PT. Remaja Rosdakarya.2003

6. Effendy, Onong Uchjana. Ilmu Teori dan Filsafat Komunikasi. Bandung: PT. Aditya Bakti.2008

7. EFENDI, Qnong Uchayana. Ilmu Komunikasi Teori dan Praktele. 2005.

8. FATIMAH, Fatimah, et al. Komunikasi Persuasif Agen Asuransi Dalam Merekrut Calon Agen (Studi Kasus Tentang Perekrutan Calon Agen Dalam Meningkatkan Penjualan Polis di Asuransi PT. AXA). Jurnal Ilmiah Komunikasi (JIKOM) STIKOM IMA, 2018, 10.02: 110-116

9. IQBAL, Muhammad, et al. Program Humas Dalam Membangun Citra Perusahaan di PT Hajjatan Media Solusindo. Jurnal Ilmiah Komunikasi (JIKOM) STIKOM IMA, 2021, 13.01: 18-24.

10. Moleong, J. Lexy, Metodologi Penelitian Kualitatif, Bandung: PT. Remaja Rosdakarya, 2006.

11. Sugiyono, Memahami Penelitian Kualitatif, Bandung : Alfabeta, 2007.

12. Sugiyono. Metode Penelitian Kuantitatif, Kualitatif, dan R\&D. Bandung: Alfabeta.2011

13. Ruslan, Rosady, Manajemen Public Relations \& Media Komunikasi Konsepsi danAplikasinya, Jakarta: Rajawali Pers

14. Rakhmat, Jalaludin. Metode Penelitian Komunikasi. Bandung: PT.Remaja Rosdakarya.2012

15. Satori,Djam'an,Metedologi Penelitian Kualitatif, Bandung : Alfabeta, 2010.

16. World Health Organization (WHO). 2020. "Q\&A on coronaviruses (COVID-19)" https://www.who.int di akses pada 14 Agustus 2020 pukul 17.30 WIB. 